\title{
From traditional paper to nanocomposite films: Analysis of global research into cellulose for food packaging
}

\author{
Manuel Garrido-Romero a, Roberto Aguado ${ }^{\mathrm{b}, *}$, Ana Moral ${ }^{\mathrm{a}}$, Celeste Brindley ${ }^{\mathrm{c}}$, \\ Menta Ballesteros ${ }^{a, * *}$ \\ ${ }^{a}$ Molecular Biology and Biochemical Engineering Dpt., Experimental Sciences Faculty, Pablo de Olavide University, Ctra. de Utrera km 1, Seville 41013, Spain \\ ${ }^{\mathrm{b}}$ CQC, Department of Chemistry, University of Coimbra, Rua Larga, 3004-535 Coimbra, Portugal \\ ${ }^{\mathrm{c}}$ Department of Chemical Engineering, University of Almeria, Almería, Spain
}

\section{A R T I C L E I N F O}

\section{Keywords:}

Cellulose

Food packaging

Film

Nanocomposite

Bacterial

Antimicrobial

\begin{abstract}
A B S T R A C T
This bibliometric study encompasses all publications between 2000 and 2020 on the production of cellulosecontaining food packaging, often proposed as an alternative to petro-based materials. Results show a fastgrowing interest in this area, especially during the last decade, with 1029 documents published in highimpact journals. In a topic where countries such as Italy, Sweden and Spain show high scientific production per capita, the most influential groups are based in European institutions (Università degli Studi di Perugia and Grenoble Institute of Technology). Among more than 7000 keywords, those with high co-occurrence were analyzed to identify not only the most important research areas, but also current knowledge gaps. It was found that composites in which cellulose is the reinforcing material, commonly as nanofibers or nanocrystals, are becoming more frequent than cellulose-based packaging. The matrix of such composites is, generally speaking, another biopolymer, but their potential to replace conventional thermoplastic materials remains under question.
\end{abstract}

\section{Introduction}

The development of novel, safe and sustainable packaging is a major concern for the food industry, which aims at conserving food and minimizing waste throughout the distribution chain, granting highquality products with a longer shelf life. As of today, most food packaging is made from petro-based plastics, accounting for an estimated production of 350 million tonnes per year (Haghighi, Licciardello, Fava, Siesler, \& Pulvirenti, 2020; Matthews, Moran, \& Jaiswal, 2021). Consequently, it is important to ensure that, once packaging materials have reached the end of their useful life, they can be degraded within a reasonable period of time without harming the environment (Bahl, Dolma, Jyot Singh, \& Sehgal, 2021; Rhim, Park, \& Ha, 2013). For this purpose, there are two possible choices. One of them is offered by petro-based biodegradable polymers, such as polycaprolactone and poly (butylene succinate), which stand out as solid options in the short term (Rudin \& Choi, 2013). Nonetheless, it is never too soon to take some daring steps towards replacing any non-renewable polymer with biopolymers, macromolecules obtained or synthesized from natural and renewable sources.

Generally speaking, all naturally found polymers, most derivatives thereof, and the so-called bioplastics fall under the hypernym "biopolymer". Among the former, cellulose is the most abundant and, given the long tradition of the manufacturing of paper and board, the prime candidate to replace petroleum-based polymers (Aguado, Murtinho, \& Valente, 2019; Klemm, Heublein, Fink, \& Bohn, 2005; Song, Murphy, Narayan, \& Davies, 2009). It has been extensively studied as a raw material in the production of biodegradable materials or films used in food because it is biocompatible, cheap, non-toxic, chemically stable, and biodegradable (Khalil et al., 2014). Cellulose can be obtained not only from wood and cotton, but also from agricultural waste, algae, or even from bacteria (Niu et al., 2020; Suhas et al. 2016). Regardless of its origin, in order to be used in food packaging, cellulose-based proposals generally imply some sort of mechanical, chemical or enzymatic process. In this context, the most widely used derivatives are cellulose micro- and nanofibers, cellulose nanocrystals, cellulose acetate, and carboxymethyl cellulose (Angel, Guo, Yan, Wang, \& Kong, 2020; Kamthai \& Magaraphan, 2017; Khalil et al., 2014).

\footnotetext{
* Correspondence to: University of Coimbra, Portugal.

$* *$ Correspondence to: Pablo de Olavide University, Seville, Spain.

E-mail addresses: rag@uc.pt (R. Aguado), mmbalmar@upo.es (M. Ballesteros).
} 
While native cellulose attains outstanding mechanical properties and carboxymethyl cellulose is a strengthening agent, their hydrophilic character imparts water permeability to packaging materials, usually undesirable in the food industry (Dufresne, 2013). This setback can be overcome by using cellulose acetate (Minelli et al., 2010). Furthermore, nanocellulose enhances the barrier properties to gases, while improving the thermal stability and the tensile strength (Vilarinho, Sanches Silva, Vaz, \& Farinha, 2018). However, by itself it offers poor resistance to water and it is therefore unsuitable for high humidity levels (Ahankari, Subhedar, Bhadauria, \& Dufresne, 2021). Instead, it is usually combined with bioplastics such as poly(lactic acid) or other biopolymers, such as polyhydroxyalkanoates, gelatin or starch, taking advantage of synergistic interactions to prepare "fully green" composite materials (Koppolu et al. 2019).

Food packaging is used.

To the best of our knowledge, previous bibliometric studies on food packaging aimed at a very broad scope, not dealing specifically with cellulose (Rodríguez-Rojas, Arango Ospina, Rodríguez-Vélez, \& Arana-Florez, 2019; Vila-Lopez \& Küster-Boluda, 2020). Such task is undertaken in this work. In light of the urgent need to reduce the current dependence on petro-based products, and considering the great advances currently taking place in the field of packaging production using cellulose and its derivatives, this is the right moment to inquire about what, where and how research is being conducted. Therefore, we have collected and curated data from a vast number of publications on the use of cellulose in food packaging, ranging between 2000 and 2020. Our study attempts to answer the following research questions, which we consider of interest to researchers and manufacturers in the field of food packaging:

What are the global trends of scientific production on cellulose used for food packaging? To what extent is technology being transferred to the food industry? Which are the journals and the research groups with most publications on this topic? Which are the collaboration relationships in terms of countries and institutions? What modifications are usually exerted on cellulose for food packaging? How has the field evolved over time? What are the main knowledge gaps and challenges to overcome?

\section{Materials and methods}

\subsection{Data collection}

The data analyzed in this paper were obtained mainly from Scopus database and, to a lesser extent, from Clarivate Analytics' Web of Science (WOS), websites widely used in bibliometric studies for obvious reasons. An exhaustive search was performed on Scopus using [TITLE$A B S-K E Y$ (Cellulose and "food packaging")] as the query string, and limiting the date of publication between 2000 and 2020. Espacenet 's search engine was used for what pertains to patents.

Data curation involved not only discriminating between articles and patents, but also relating the number of documents in each case to the year of publication, the institutions and countries involved, and the journals hosting those publications. The main research networks between different countries could be visualized by means of VOSviewer software (Leiden University), also allowing to elucidate where the research on cellulosic food packaging is in vogue and where it seems past its peak. Documents listing more than 10 countries for their authors' affiliations were discarded. Finally, a search by author on Scopus retrieved the key data from each of the most prolific researchers.

\subsection{Analysis of keywords}

In each case, both the keywords provided by the authors and the indexed keywords (i.e., those which are due to the search engine) were considered. First, synonymous terms were manually merged, e.g.: nanofibrillar cellulose, nanofibrillated cellulose, cellulose nanofibrils and cellulose nanofibers were all merged into the latter. To ease visualization, acronyms were generally favored, and thus polylactic acid, poly(lactic acid), poly lactic acid and PLA are consistently expressed in the latter's form. Poly(vinyl alcohol), polyvinyl alcohol and $P V O H$ are expressed as $P V A$. Likewise, Fourier transform infrared spectroscopy, atomic force microscopy, thermogravimetric analysis, transmission electron microscopy and scanning electron microscopy were replaced with FTIR, AFM, TGA, TEM and $S E M$, respectively, regardless if their full name was more commonly found than the abbreviation. Needless to say, the singular form and the plural form of the same noun (nanocrystal, nanocrystals) were equally merged.

Generic keywords like article, priority journal, procedures, review, or Scopus, were manually removed. More arguably, but necessarily to avoid redundancy, non-human animals was merged with animals, since hardly any of these documents was found to speak in terms of "human animals". Furthermore, documents in categories not related to the subject of this bibliometric study, such as humanities, arts, or social sciences, were also discarded. Out of 7019 keywords identified in all the articles analyzed in this bibliometric study, only those with at least 30 repetitions were chosen.

VOSviewer software was used for the purposes of clustering. This allowed for a rapid and intuitive visualization of the association between keywords, representing them with nodes, which are then linked by lines representing the degree of co-occurrence (van Eck \& Waltman, 2010). A chronological overlay of the keywords, highlighting the year of highest occurrence, was also represented.

\section{Results and discussion}

\subsection{Progression of scientific production}

Fig. 1 shows the evolution in the number of documents related to the manufacture of cellulose-containing food packaging over the past twenty years, reaching a total of 1029 manuscripts. This evolution can be fitted to an exponential function with $\mathrm{R}^{2}>0.97$ and a rate of growth of $0.23 \mathrm{yr}^{-1}$, clearly higher than that of the general number of publications (Bornmann \& Mutz, 2015). Therefore, there is growing interest in this subject, due to the emerging and current need to manufacture food packaging from sustainable and biodegradable materials. The transfer of this knowledge to the food industry is also undoubtedly relevant, based on the number of patents granted for producing cellulose-based or cellulose-reinforced food packaging, which has tripled in less than two decades (Fig. 1).

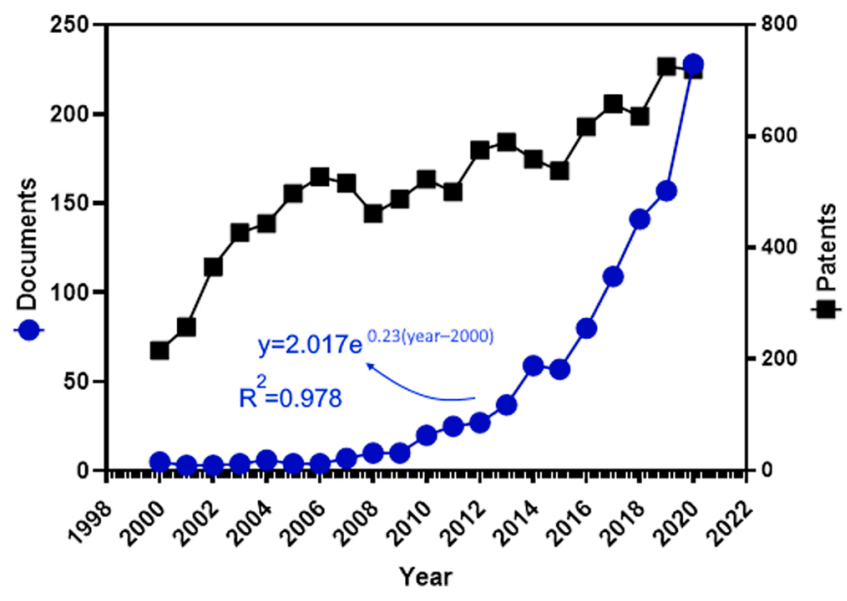

Fig. 1. Trend in the number of publications and patents per year for the manufacture of cellulose-containing food packaging in the period 2000-2020. 


\subsection{Distribution of papers in research journals}

The impact factor of a journal is defined as the ratio between the number of citations in a year and the number of citable articles published in the previous two years (Brink, 2013). Another parameter widely used to measure the impact of journals is their position within a category. Fig. 2 shows the relationship between the four journals with the most articles related to research on the manufacture of cellulose-containing food packaging, presented in decreasing order as follows: Carbohydrate Polymers (92 publications), International Journal of Biological Macromolecules (81 publications), Cellulose (37 publications), and Food Hydrocolloids (26 publications). All these journals lie within the first quartile (Q1) and have a major impact on scientific society. Consistently, the journal with the highest impact index, Carbohydrate Polymers, is also the preferential choice of most authors, as it accounts for the greatest number of publications. The journal with the second highest impact index is Food Hydrocolloids, ranked fourth in terms of the number of articles. Below these two journals are International Journal of Biological Macromolecules and Cellulose. Carbohydrate Polymers is not only a Q1 journal, but also indexed within the first decile for Applied Chemistry, Organic Chemistry and Polymer Science. Cellulose is in the first decile in two fields of Materials Science: Paper and Wood and Textiles. Finally, Food Hydrocolloids belongs to the first decile in Applied Chemistry and Food Science and Technology.

\subsection{Distribution of publications by country}

Fig. 3 A shows the fifteen most prolific countries (out of a total of 74) in research regarding this bibliometric analysis and the number of publications produced since 2000. Seven countries have published more than 50 articles in this area. The list is led by China with more than 200 documents, followed by the US. However, these two nations also account for the highest populations of researchers: 1.9 million in the case of China, 1.2 million in the US (OECD, 2021). The light green columns in Fig. 3 A show the ratio between the number of publications on cellulose-containing food packaging and the number of researchers. In this sense, there is little doubt that the most efficient country in what pertains to this topic, and at least among those of which the website OECD.org offers enough data, is Italy (52.5 per 100,000 researchers).

It should be noted, nonetheless, that obtaining the most reliable estimation for the number of researchers in each case was not a straightforward task. The procedure is explained in detail in the Supplementary Information. Briefly, the headcount from OECD data was used whenever possible, compiling the data for the total year range considered (2000-2020) and calculating the mean number over that given period of time. For the US and Canada, a headcount was not available, but results were obtained from the number of researchers per thousand employed people. Furthermore, Table S1 offers the ratio of documents to population of working age (World Bank, 2019), a statistic where Sweden (5.1 per 100,000 people) clearly dominates.

Fig. 3B shows the ten countries that have secured the most patents in this field, starting by the United States with more than 6500 inventions. Comparing the two figures, the disparity between academic works and patents is nothing short of remarkable, with the exceptions of Italy and the US, some of whose institutions are major players in both areas. Japan and Germany, with their strong protection of intellectual property (Nagaoka, 2005), are second and third to the US in patents granted, but not even within the 20 most prolific countries when it comes to scientific production. On the other hand, China, India, Iran and Brazil, four countries within the top 6 of scientific production, account for few patents on cellulose-containing food packaging. To our judgment, the relatively less effective protection of intellectual property rights in those nations, in comparison with the major players in Fig. 5B, discourage researchers and institutions from filing a patent, even when the invention is undoubtedly worthy of protection. Nonetheless, they turn what could be a setback into an outstanding contribution to the scientific community worldwide.

It is not less important to address the network of links between countries that have published jointly on this subject. Fig. 4 is presented in such a way that only 75 lines of collaboration, corresponding to the highest association strength, are displayed. The thickness of these lines represents the number of collaborations between institutions from different countries. Understandably, there is little doubt about the influence of geographical and language factors. We can identify a collaboration network comprising Spain, Mexico, Chile, Portugal (not shown), Brazil, Argentina and Italy, although the latter is linked to many other European countries. Malaysia, Taiwan (not shown), Indonesia, the Philippines (not shown), and Australia are prone to take part in joint publications. Of particular note is the fact that the most prolific countries with regard to the number of papers on this subject, China and the United States, establish a large number of collaborative partnerships with one another and with many other nations.

It is worth mentioning that France, Denmark, Sweden, Finland (not shown) and the United Kingdom, five European countries with relevance on the topic and with a noticeable degree of inter-collaboration, are displayed in blue. Their scientific production on cellulose-containing food packaging used to be remarkable between 2012 and 2015 but, as of today, the topic seems to be hotter in China, Iran, Malaysia, Indonesia, South Korea, and Egypt.

\subsection{Remarkable research groups and their publications}

Some prolific research groups or institutions, having produced ten or more publications on the subject of this bibliometric study, are

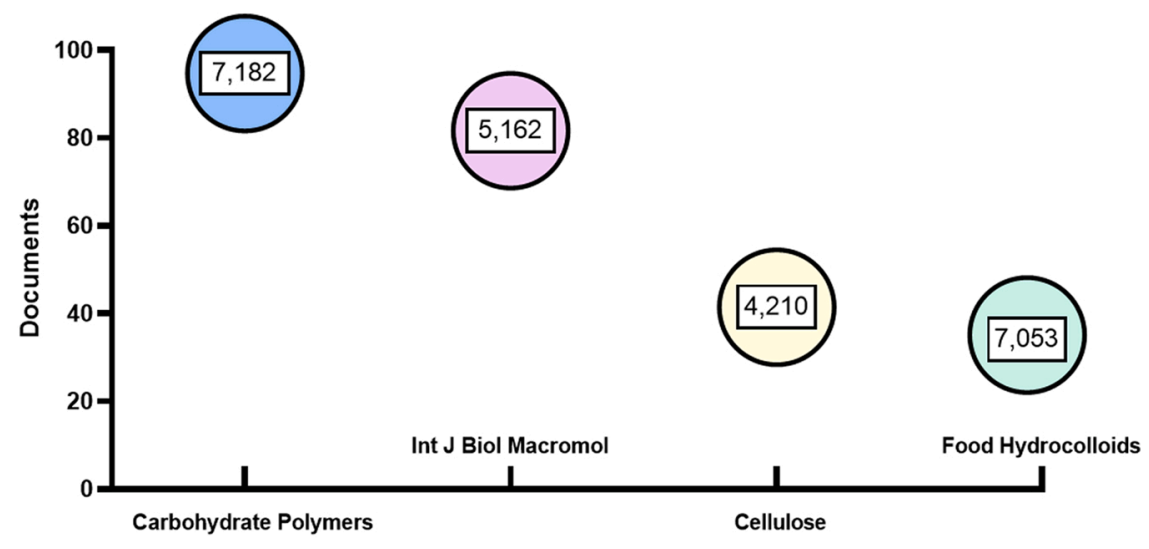

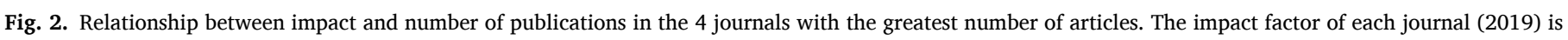
given within the circles. 

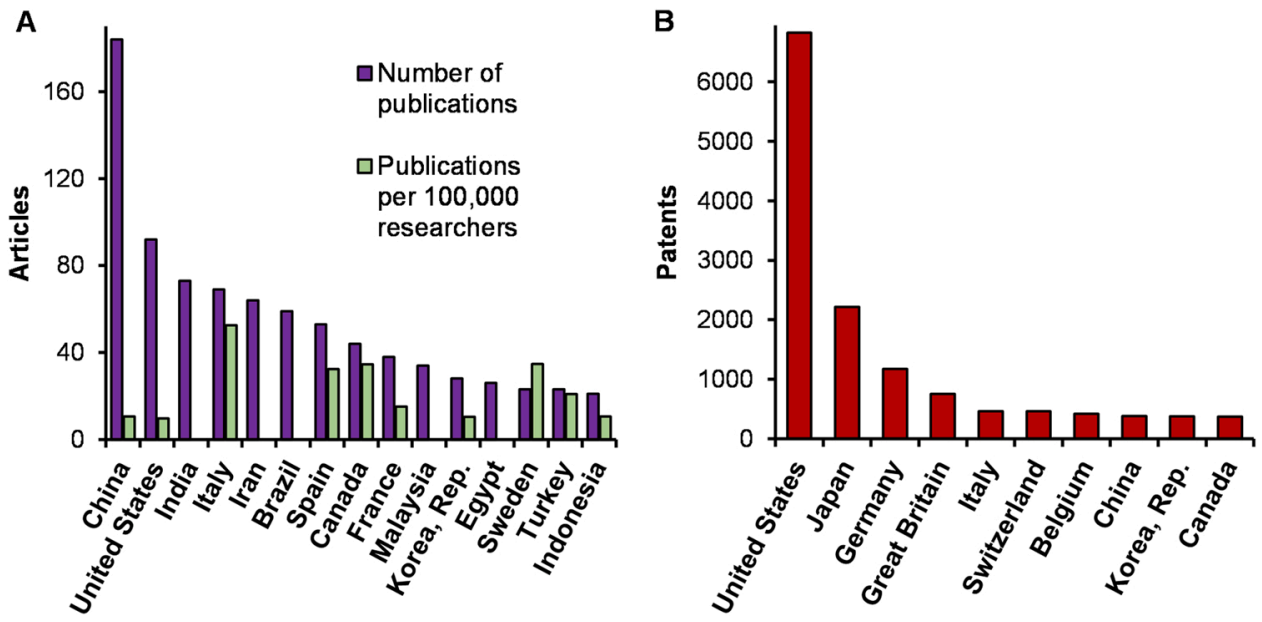

Fig. 3. The 15 countries with the highest number of publications, showing the ratio to the population of researchers when available (A), and the 10 countries with most patents (B).

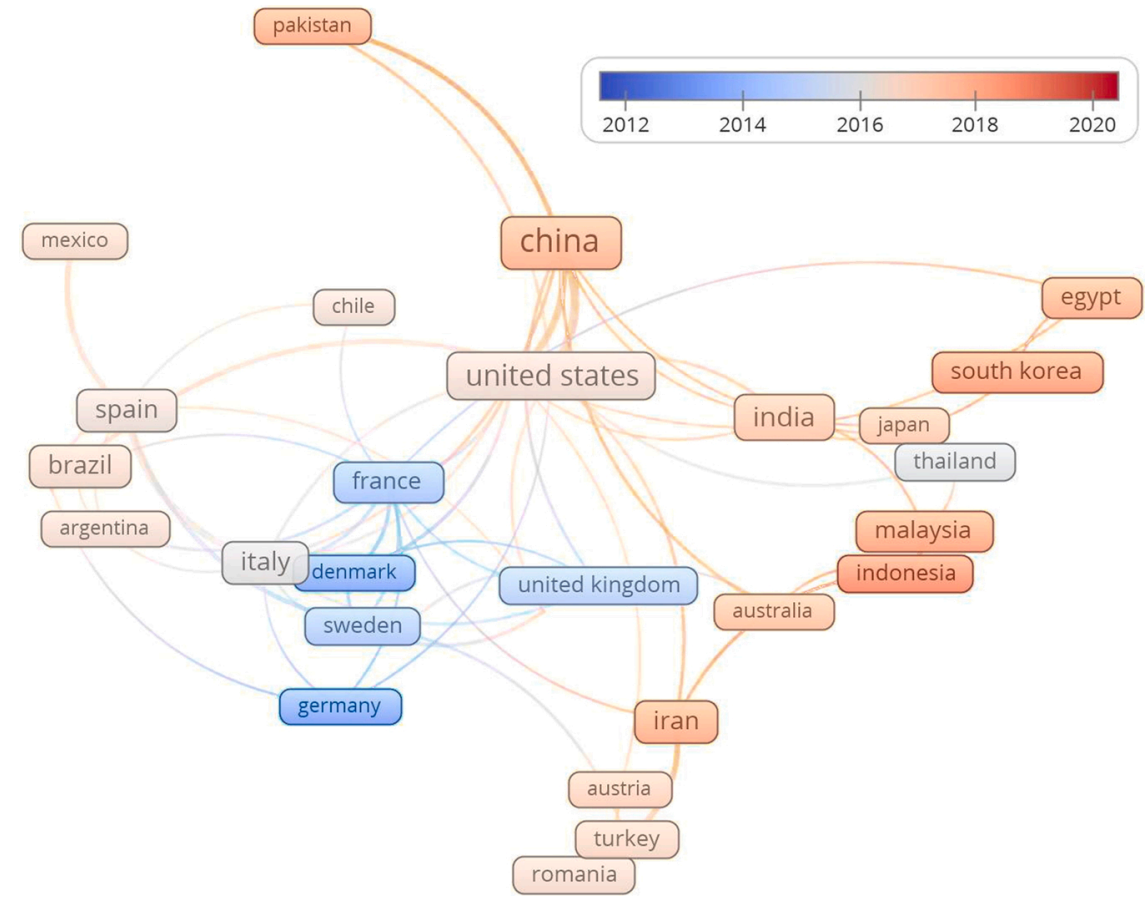

Fig. 4. Collaborations between research centers by country, as a function of the date of publication. (For interpretation of the references to color in this figure, the reader is referred to the web version of this article).

presented in Table 1. The absence of Chinese and American authors indicates that the publications generated in these countries are not carried out by groups focused on this research topic. Instead, they conduct research into other fields, such as bioplastics or antimicrobial materials, and they apply the knowledge gathered to food packaging on a more tangential or occasional basis. In contrast, in certain Western European institutions there are groups with a strong track record in research on cellulose-based food packaging, such as the Università degli Studi di Perugia (Fortunati and co-workers), PackLAB group (Milan), and LGP2 (Grenoble).

Urmia University is the only public institution where documents are significantly split between two different departments, although with occasional co-authoring. Other prolific affiliations are the BioNanocomposite Research Center (Seoul) and EMBRAPA, with presence in several Brazilian cities. Interestingly enough, the most widely covered topics by all these groups encompass nanocellulose, oxidized cellulose and nanowhiskers (also known as nanocrystals), even though nanoscale cellulose rarely constitutes the bulk of a packaging material (Bettaieb et al., 2015; Phanthong et al. 2018). Oxidized cellulose, on the other hand, is a cellulose derivative whose carboxyl groups can confer antimicrobial properties to food packaging, but it is usually proposed as an additive (Aydemir Sezer, Sanko, Yuksekdag, Uzundağ, \& Sezer, 2016).

Of all the documents selected in this bibliometric study, some stand out with a particularly high number of citations. Table 2 displays the four most cited research articles and the four most cited reviews in the last decade (2011-2020). Highlighting their applications in the food packaging sector, the review of Rhim et al. (2013), with 944 citations, focuses on bio-nanocomposites, their mechanical, barrier and antimicrobial properties, and their biodegradability. Also, it includes safety considerations emphasizing the problem of migration of nanoparticles and its impact on human health. Perhaps from a more technical point of view, the review by Khalil et al. (2014) pays attention on cellulose and 


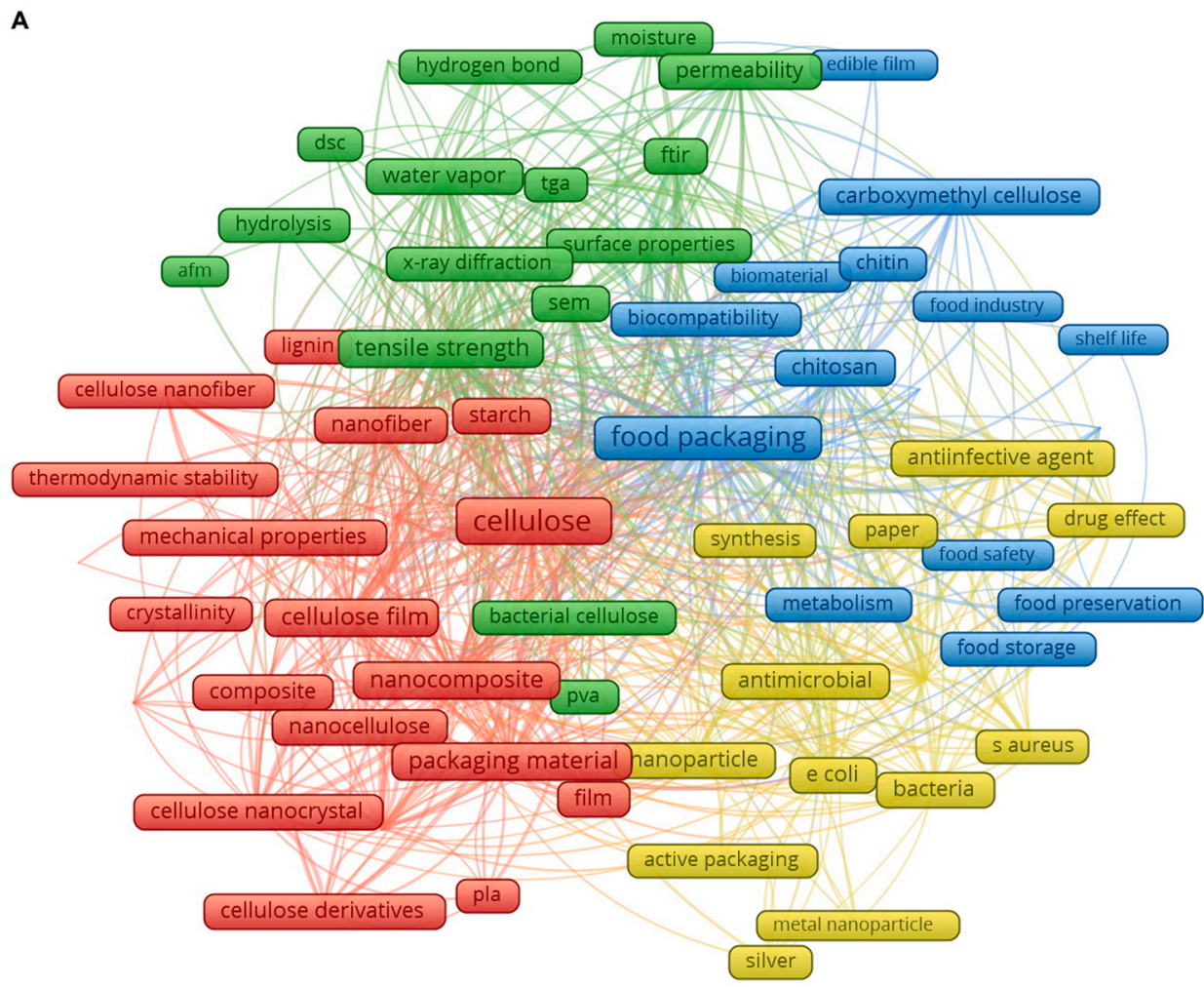

B

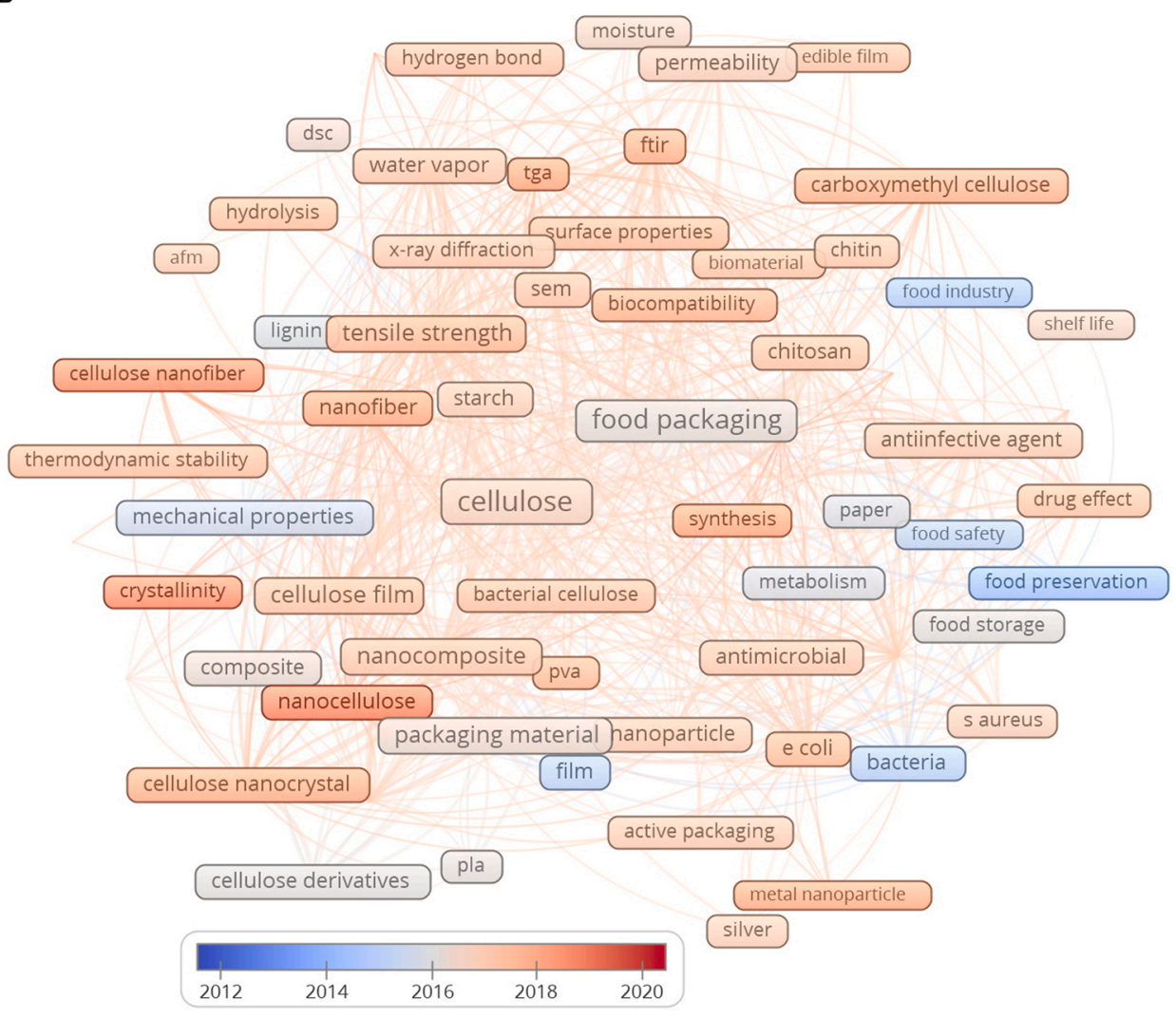

Fig. 5. (A) Clusters of keywords in publications on the manufacturing of cellulose-containing food packaging; (B) evolution of said keywords through the period 2012-2020. (For interpretation of the references to color in this figure, the reader is referred to the web version of this article). 
Table 1

Prolific groups in terms of publications on cellulose-containing food packaging.

\begin{tabular}{|c|c|c|c|}
\hline Center/University & Country & Documents & Most contributed topics \\
\hline $\begin{array}{l}\text { Empresa Brasileira de } \\
\text { Pesquisa Agropecuária- } \\
\text { EMBRAPA } \\
\text { L.H.C. Mattoso, H.M.C. } \\
\text { Azeredo, M.F. Rosa et al. }\end{array}$ & Brazil & 19 & $\begin{array}{l}\text { Active Food Packaging; } \\
\text { Bionanocomposites; } \\
\text { Edible Films; } \\
\text { Nanotechnology; Pectin; } \\
\text { Starch }\end{array}$ \\
\hline $\begin{array}{l}\text { Grenoble Institute of } \\
\text { Technology } \\
\text { LGP2: J. Bras, A. } \\
\text { Dufresne, C. Sillard, N. } \\
\text { Belgacem et al. }\end{array}$ & France & 14 & $\begin{array}{l}\text { Active Packaging; } \\
\text { Biomaterials; } \\
\text { Nanocellulose; } \\
\text { Nanocomposites; } \\
\text { Nanowhiskers; Oxidized } \\
\text { Cellulose }\end{array}$ \\
\hline $\begin{array}{l}\text { Kyung Hee University } \\
\text { BioNanocomposite } \\
\text { Research Center: Rhim } \\
\text { J.-H., S. Roy, et al. }\end{array}$ & $\begin{array}{l}\text { Korea, } \\
\text { Rep. }\end{array}$ & 10 & $\begin{array}{l}\text { Active Food Packaging: } \\
\text { Bionanocomposites; } \\
\text { Chitosan; E. coli; } \\
\text { Nanocomposite films }\end{array}$ \\
\hline $\begin{array}{l}\text { Università degli Studi di } \\
\text { Milano } \\
\text { PackLAB: L. } \\
\text { Pergiovanni, E. } \\
\text { Mascheroni, S. Farris, S. } \\
\text { Limbo, et al. }\end{array}$ & Italy & 21 & $\begin{array}{l}\text { Nanocellulose; Oxidized } \\
\text { Cellulose, Nanowhiskers; } \\
\text { Paperboards; Edible } \\
\text { Films; Active Food } \\
\text { Packaging }\end{array}$ \\
\hline $\begin{array}{l}\text { Università degli Studi di } \\
\text { Perugia } \\
\text { Civil and Environmental } \\
\text { Eng. Dpt.: E. Fortunati, } \\
\text { J.M. Kenny, D. Puglia, } \\
\text { et al. }\end{array}$ & Italy & 23 & $\begin{array}{l}\text { Bioplastics; } \\
\text { Nanocellulose; Oxidized } \\
\text { Cellulose, Nanowhiskers; } \\
\text { Kraft Lignin; Pulping; } \\
\text { Kenaf Fibers; Sisal, Coir }\end{array}$ \\
\hline $\begin{array}{l}\text { Urmia University } \\
\text { Food Science and } \\
\text { Technology Dpt.: H. } \\
\text { Almasi et al.; Food } \\
\text { Hygiene and Quality } \\
\text { Control Dpt.: M. Moradi, } \\
\text { H. Tajik, et al. }\end{array}$ & Iran & 18 & $\begin{array}{l}\text { Edible Films; Active Food } \\
\text { Packaging; } \\
\text { Nanocellulose; Cellulose } \\
\text { Films; Packaging Films; } \\
\text { Thymol }\end{array}$ \\
\hline
\end{tabular}

Table 2

List of the four most cited reviews and the four most cited original research articles, published from 2011 onwards, that are found with the search string "cellulose AND food packaging". Cit.: citations (Scopus).

\begin{tabular}{|c|c|c|c|}
\hline \multirow{2}{*}{$\begin{array}{l}\text { Most cited review articles } \\
\text { Document }\end{array}$} & \multirow[b]{2}{*}{ Cit. } & \multicolumn{2}{|l|}{ Most cited research articles } \\
\hline & & Document & Cit. \\
\hline $\begin{array}{l}\text { Bio-nanocomposites for food } \\
\text { packaging applications (Rhim } \\
\text { et al., 2013) }\end{array}$ & 944 & $\begin{array}{l}\text { Multifunctional } \\
\text { bionanocomposite films of poly } \\
\text { (lactic acid), cellulose } \\
\text { nanocrystals and silver } \\
\text { nanoparticles (Fortunati et al., } \\
\text { 2012a) }\end{array}$ & 394 \\
\hline $\begin{array}{l}\text { Production and modification of } \\
\text { nanofibrillated cellulose using } \\
\text { various mechanical processes: } \\
\text { A review (Khalil et al., 2014) }\end{array}$ & 686 & $\begin{array}{l}\text { Effects of modified cellulose } \\
\text { nanocrystals on the barrier and } \\
\text { migration properties of PLA } \\
\text { nano-biocomposites (Fortunati } \\
\text { et al. } 2012 \mathrm{~b} \text { ) }\end{array}$ & 319 \\
\hline $\begin{array}{l}\text { Polysaccharide-based films and } \\
\text { coatings for food packaging: A } \\
\text { review (Cazón, Velazquez, } \\
\text { Ramírez, \& Vázquez, 2017) }\end{array}$ & 389 & $\begin{array}{l}\text { Synthesis, characterization and } \\
\text { antibacterial activity of } \\
\text { biodegradable starch/PVA } \\
\text { composite films reinforced with } \\
\text { cellulosic fiber (Priya, Gupta, } \\
\text { Pathania, \& Singha, 2014) }\end{array}$ & 216 \\
\hline $\begin{array}{l}\text { Bionanocomposites materials for } \\
\text { food packaging applications: } \\
\text { Concepts and future outlook ( } \\
\text { Youssef \& El-Sayed, 2018) }\end{array}$ & 223 & $\begin{array}{l}\text { Development of cellulose-based } \\
\text { bactericidal nanocomposites } \\
\text { containing silver nanoparticles } \\
\text { and their use as active food } \\
\text { packaging (de Moura, Mattoso, } \\
\text { \& Zucolotto, 2012) }\end{array}$ & 203 \\
\hline
\end{tabular}

specifically nanofibrillated cellulose, discussing its major drawbacks, namely the high energy consumption of mechanical fibrillation, and emphasizing on pretreatments to overcome this problem and its several applications, such as food packaging.

In the list of the most cited articles, two studies on composites of poly (lactic acid) and cellulose nanocrystals stand out with 394 and 319 citations. Both represent an important advance in the field of bionanocomposite films. Moreover, the most cited manuscript of the two incorporates silver nanoparticles to grant antimicrobial properties, obtaining a material with good perspectives for food packaging due to its low water permeability, good oxygen barrier properties and migration level below the legislated limits.

\subsection{Keyword analysis}

Most of the 7019 keywords appeared only once along the search results, as setting the minimum number of appearances to be listed at 2 reduced the number of keywords to 2347.95 terms satisfied the minimum requirement of 30 repetitions, although other important concepts with less occurrence are discussed below to highlight how certain aspects are being overlooked. Fig. 5A shows the distribution of keywords according to their co-occurrence. Four clusters, topics or keyword communities were identified with different colors, setting the size of the label in accordance with their abundance in the literature. It should be noted that, while all representative terms are displayed, many of the 95 keywords, generally subordinate terms, are hidden for the sake of clear visualization.

Furthermore, if the analysis is performed according to the importance of the keywords over a certain period of time, in this case 2012-2020, we can picture the evolution of research trends in what pertains to each of the main topics. This is depicted as a heat map in Fig. 5B. As a vague generalization, keywords related to the properties of passive food packaging and to traditional components are presented in bluish frames, while the reddish tones of keywords generally associated to active food packaging provide valuable information about the current trends.

\subsubsection{Red cluster: nanocellulose as reinforcing material}

Many publications that fall within the scope of the red cluster are authored by research groups with presence in Table 1. Clearly, nanocellulose (118 appearances) stands out, along with hyponyms such as cellulose nanocrystal (159) and cellulose nanofiber (74), plus terms that are probably (but not necessarily) subordinate such as nanocrystal (103) and nanofiber (119). The fact that nanoscale cellulose is seldom reported as the main constituent of the packaging material (235) is evidenced by the co-occurrence of reinforcement (57), composite (88), composite film (58) and especially nanocomposite (249). Thus, cellulose-based materials do not prevail here. All-cellulose proposals (Ghaderi, Mousavi, Yousefi, \& Labbafi, 2014; Boufi et al. 2016) are outweighed by composites whose dispersed phase is nanocellulose and whose continuous phase is another polymeric material, most frequently another biopolymer (Nešić et al. 2020). Starch (111), PLA (65) and lignin (48) are the most frequent choices for a composite matrix, while none of the different poly (hydroxyalkanoates), such as poly(hydroxybutyrate), met the requirement of 30 repetitions. The main aims of nanocellulose reinforcements, albeit not the only ones, are improving mechanical properties (122) and thermodynamic stability (37).

As shown in Fig. 5B, research on nanocellulose is a hot topic as of today, while those keywords associated with composite matrices (starch, $P L A$, lignin) tended to appear more frequently in old publications. However, this does not mean that nanocellulose is becoming the primary material in recent proposals, as in the case of the so-called cellulose nanopapers. A search with the query string [TITLE-ABS-KEY (Nanocellulose and "food packaging")] shows that nanofibers, nanocrystals and bacterial cellulose are, up to date, generally used as reinforcement (Gan \& Chow, 2018). The shift, then, seems to be from both fibers and nanofibers from cellulose (674) to a clear prevalence of the latter. Nonetheless, the commercialization of nanocellulose on a large scale is still difficult because of its high prices, at least $50 € / \mathrm{kg}$ (Markets \& Markets, 2020). In any case, and often defeating the purpose of taking advantage of the high availability of cellulose, proposals for 
cellulose-containing food packaging are seldom cellulose-based (Bideau, Loranger, \& Daneault, 2018), but often cellulose-reinforced.

\subsubsection{Yellow cluster: active packaging}

The umbrella term active packaging (68) encompasses virtually any function other than passive containment, such as the control of storage conditions, antioxidant (82) activity to prevent the oxidative degradation of food components, and some missing but important properties. A missing function, for instance, is anticounterfeiting, which is generally only considered for the packaging of branded products, but foodstuff falsification is actually a major problem (Śliwińska, Wiśniewska, Dymerski, Namieśnik, \& Wardencki, 2014), too often overlooked. In any case, antimicrobial (146, plus 120 appearances of antiinfective agent) packaging outweighs any other kind of active packaging among the search results (Fig. 5A).

The antibacterial applications of silver (46) were already, although inadvertently, exploited by Phoenicians ca. 2800 years ago to store liquids. This and other transition metals, also providing antimicrobial properties to the food packaging material, are usually incorporated as nanoparticles (122, plus 35 occurrences for metal nanoparticle). The most common targets are Staphylococcus aureus (83), as a representative Gram-positive bacteria, and Escherichia coli (126), as example of Gramnegative bacteria. Listeria monocytogenes, one of the bacteria (96) found in the search results, did not make the cut, and, unexpectedly, neither did fungi or Candida albicans. All things considered, this so-called antimicrobial packaging often is only proven as antibacterial (125), but scarcely as antifungal, even though fungal colonization is a more dangerous threat for crop products (Avery, Singleton, Magan, \& Goldman, 2019). Furthermore, the use of silver and other metal transitions in food packaging remains under question because of their cytotoxicity (Garza-Cervantes et al. 2020), which allows us to identify an opportunity for the development of antimicrobial packaging on the basis of biocompatible agents. These may include essential oils (45), more related to the keywords in the blue cluster, and derivatives resulting from synthesis, the clearest trend-setting term (Fig. 5B).

A subset of active packaging that did not make the cut, but that we expect to grow notoriously in the short term, is intelligent packaging. This comprises the development of visual sensors to provide information about the foodstuff contained, e.g., for $\mathrm{pH}$ to indicate freshness of meat and fish (Mohebi \& Marquez, 2015), for the detection of volatile gases (Freitas et al., 2020), or to detect whether the product has been stored at excessive temperatures, the presence of harmful gases or an increase in acidity when protecting dairy products (Rojas-Lema et al., 2020). Unfortunately, intelligent packaging is not common in the market, owing mainly to its high cost, which translates into a significant increase in the final price of the product for the consumer.

\subsubsection{Green cluster: analytical techniques to characterize cellulose- containing packaging}

As found for the keywords of the red cluster (Fig. 5A), the prevalent procedure to produce cellulose-containing food packaging is the formation of a composite film, and not of paper and board, which are the most common materials for food protection in the market. That said, samples of such films are often analyzed by FTIR (129), by SEM (137), by $X$-ray diffraction (75) to evaluate crystallinity, and by TGA (79) for the thermal stability, a particularly frequent concern in recent publications (Fig. 5B). Most importantly, mechanical properties are almost always quantified by measuring the tensile strength (250) or, in what could be considered a subordinate term, the elongation at break (30), but rarely referring to the resistance to burst and tear. Other techniques that made the cut were differential scanning calorimetry (38), AFM (33), and goniometry to measure the contact angle (39), indicating how hydrophobic a surface is. But when it comes to food packaging, the most important surface properties (52) are those of barrier to water (60), oxygen (53), and oils and fats (41). This is why permeability (98) tests are widely found in the literature. Indeed, a common problem of native cellulose-based materials, and one of the reasons why nanocellulose-reinforced materials are outweighing them, is the low tolerance to water vapor (162). This is, therefore, a major concern for any manufacturer wishing to produce cellulose-based or cellulose-containing food packaging.

Besides the characterization techniques grouped in the green cluster, a bacterial culture is common practice to test the alleged antimicrobial properties of the proposed solutions. Nonetheless, the use of bacteria is not always meant to combat them, but also to produce bacterial cellulose (64), a type of nanocellulose with outstanding mechanical and gas barrier properties (Padrão et al., 2016). Fig. 6A shows that very few articles proposed bacterial cellulose (in general) before 2008, but its popularity has grown fast as of lately. In the context of food packaging, the mode year, i.e., the year when the keyword bacterial cellulose showed more appearances, was 2017. Unlike cellulose from wood, cellulose from bacteria is readily obtained as nanocellulose, avoiding the need of chemical and mechanical treatments that lignocellulosics require (e.g., fibrillation for nanofibers and acid hydrolysis for nanocrystals).

Not surprisingly, given its versatility, bacterial cellulose is related to terms of all clusters (Fig. 5A). The main drawback of this biocompatible, strong and superabsorbent material, whose promising medical applications are out of question, is the lack of feasibility for its industrial production.

\subsubsection{Blue cluster: Desired properties for the food industry}

A final cluster of keywords is characterized by inter-related, coconcurrent objectives (Fig. 5A). Generally speaking, these objectives are familiar, expectable, and rather conceptual: biocompatibility (51), biodegradability (159), edible film (36), food preservation (66), food safety (33), and extended shelf life (31). With the exception of edible, these terms are far from concrete. It should be noted that chitin (48), chitosan (133) and carboxymethyl cellulose (92) are edible biopolymers (105), commonly used in foodstuff, and at the same time they help with food preservation by granting antimicrobial and antioxidant activity.

The functional groups of native cellulose (Fig. 6B) may not be enough to satisfy certain needs. This is why esterification towards cellulose acetate, more resistant to water (Angel et al. 2020), and etherification towards carboxymethyl cellulose, which provides strength and resistance to oils and fats (Kamthai \& Magaraphan, 2017), are common choices. An example of application of this derivative, involving synergistic interactions with other polysaccharides, is combining it with sodium alginate and chitosan biguanide hydrochloride to improve the antimicrobial capacity of the packaging and prevent food shrinkage (Salama, Abdel Aziz, \& Alsehli, 2019). Among all derivatives produced by chemical functionalization, carboxymethyl cellulose is the most frequently found material (Fig. 6).

Nonetheless, there is some discrepancy between the advantages that are alleged and the parameters that are measured. Antioxidant activity, usually granted by the aforementioned carboxymethyl cellulose or by essential oils (45), are usually taken for granted owing to the nature of those compounds. Still, free radical scavenging assays, the spectrophotometric quantification of 2,2-diphenyl-1-picrylhydrazyl being the most popular one (Menzel, 2020), were not found among the techniques of the previous cluster (Fig. 5A). Likewise, biodegradability, being a term with so many repetitions, is usually stated as a major objective whereas anaerobic or aerobic degradation are not experimentally confirmed. In some cases, additions and reactions intended to achieve antimicrobial properties hamper biodegradability. For instance, it is known that silver nanoparticles severely slow down the rate of degradation of PLA (Gorrasi, Sorrentino, \& Pantani, 2015), and that even natural polymers lose their biodegradability by becoming highly substituted with quaternary ammonium groups (Sharma et al. 2020). Hence, biodegradability should not be assumed from the sole fact of using polysaccharides as a major constituent of packaging materials.

Finally, another important issue is the possible threat for human health of the use of nanocellulose in food packaging. Unlike microcrystalline cellulose, nanocellulose has not yet been designated as 


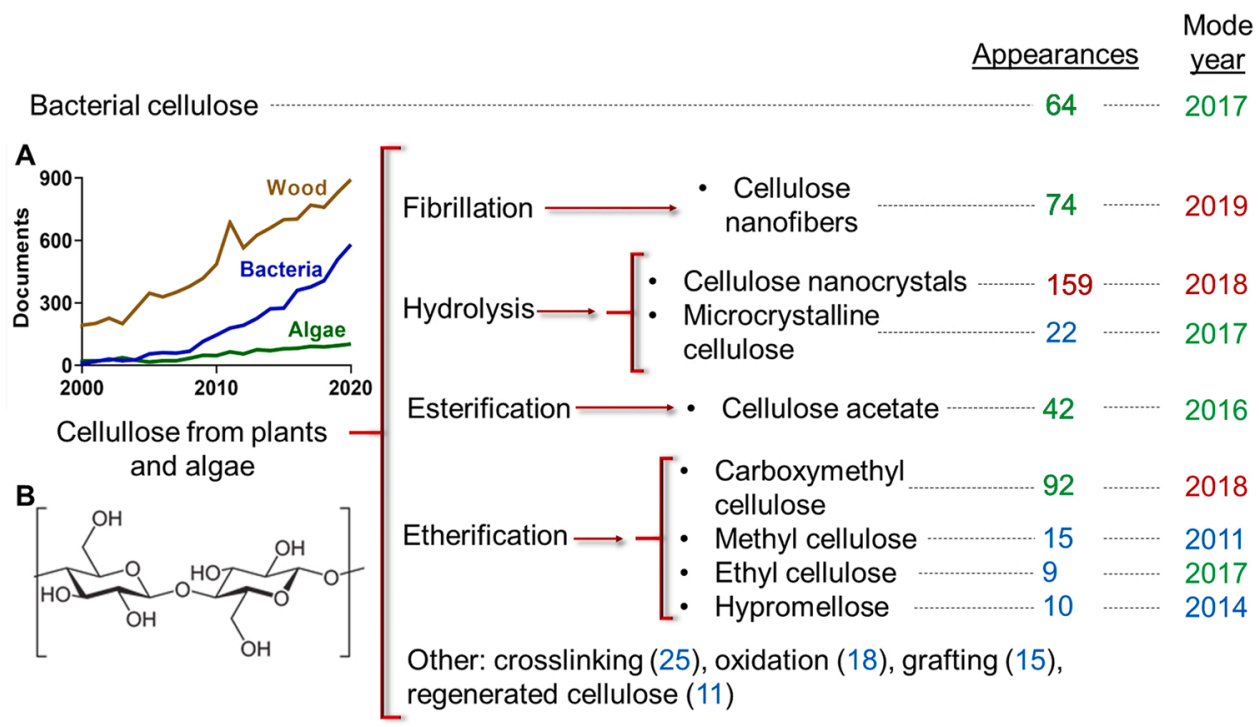

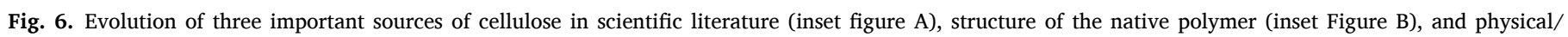
chemical processes undergone to produce some of the materials that have been proposed for food packaging.

"generally regarded as safe" (GRAS). Therefore, its release from food packaging could cause a potential risk to human health and it is not currently authorized for food contact applications. Recently, the European Food Safety Authority published a guide on the risk assessment of nanotechnology applications in the food and feed chain, giving advice on the testing and methods to apply (EFSA Scientific Committee, 2018). Several researchers have evaluated the safety of nanocellulose according to these recommendations, although studies are still scarce and, in some cases, ambiguous (Silva, Dourado, Gama, \& Poças, 2020; Thomas et al., 2020). Toxicological studies of ingested nanocellulose (in vitro and in vivo systems) suggest that it has slight acute toxicity, but further experiments are needed to elucidate the health implications in the long term (DeLoid et al., 2019; Khare et al., 2020).

\section{Conclusions}

Over the course of this bibliometric study, it was shown that the number of research articles on the use of cellulose for food packaging has increased with a rate of exponential growth of $0.23 \mathrm{yr}^{-1}$ since year 2000 , making this a research area with outstanding scientific production. In terms of the distribution of publications by countries and institutions, China, the US, and India account for more than $40 \%$ of the world's production, with a large network of joint collaborations. Nonetheless, Italy accounts for the highest number of publications per 100,000 researchers, mostly thanks to highly prolific groups belonging to the Università degli Studi di Perugia and to the Università degli Studi di Milano. The US, Japan and Germany lead when it comes to secured patents, but there was no correlation between patents and publications. This is not due to matters of pure or applied research, as the vast majority of publications collected by us fall into the latter category, but to a still weak protection of intellectual property rights in China, India, Iran and Brazil. To a lesser extent and in comparative terms, the same could be said of Spain or Canada, whose enforcement of patent laws is less effective than that of Germany or the US, respectively.

An analysis of the keywords evidenced some remarkable discrepancies between research and markets. Traditionally and still as of today, most cellulosic food containers in the market are primarily made out of paper or board. However, when it comes to the recent literature, the presence of cellulose as a reinforcing material, and frequently in its nanoscale form, outweighs the use of cellulosic matrices. This involves the choice of materials whose feasibility for mass production is under question, such as bioplastics like poly(lactic acid), nanowhiskers, bacterial cellulose, and chitosan. Moreover, further research, both related to the manufacturing process and to toxicity studies, is necessary to ensure that nanocellulose-containing packaging can be regarded as safe.

While antimicrobial properties are almost ubiquitous among the proposals found, we should approach them critically. First, fungi threat the security of food supply as much as bacteria, and yet antimicrobial assays are, more often than not, antibacterial assays only. Second, among the great potential applications of active packaging, antimicrobial and antioxidant activity overshadow the rest, although some recent articles integrate promising sensor systems in food packaging materials. Third, the concepts of antimicrobial packaging and biodegradability are frequently found together in cellulosic food packaging, but the latter term tends to be taken for granted because of the presence of cellulose and/or other biopolymers. However, the antimicrobial components considered in many proposals, such as silver nanoparticles, can hamper biodegradability, which then should not be mentioned as an advantage or as a source of motivation unless actually tested.

\section{Funding Source}

Funding for open access publishing: Universidad Pablo de Olavide/ CBUA (Consortium of University Libraries of Andalusia). These institutions had no involvement in the collection or interpretation of data, or in the decision to submit the article for publication.

\section{CRediT authorship contribution statement}

Manuel Garrido-Romero: Data curation, Formal analysis, Investigation, Methodology, Roles/Writing - original draft. Roberto Aguado: Formal analysis, Methodology, Roles/Writing - original draft, Writing - review \& editing, Validation. Ana Moral: Project administration, Resources, Software, Supervision, Validation. Celeste Brindley: Data curation, Formal analysis, Investigation, Writing - review \& editing. Menta Ballesteros: Data curation, Methodology, Roles/Writing original draft, Writing - review \& editing, Supervision, Validation. The corresponding authors state that all authors made substantial contributions to the conception and design of the study, or acquisition of data, or analysis and interpretation of data; drafting the article or revising it critically for important intellectual content, and final approval of the version to be submitted. 


\section{Declarations of interest}

The authors declare that there is no conflict of interest.

\section{Acknowledgments}

The authors would like to thank Universidad Pablo de Olavide for its support.

\section{Appendix A. Supporting information}

Supplementary data associated with this article can be found in the online version at doi:10.1016/j.fpsl.2021.100788.

\section{References}

Aguado, R., Murtinho, D., \& Valente, A. J. M. (2019). A broad overview on innovative functionalized paper solutions. Nordic Pulp and Paper Research Journal, 34(4), 395-416. https://doi.org/10.1515/npprj-2019-0036

Ahankari, S. S., Subhedar, A. R., Bhadauria, S. S., \& Dufresne, A. (2021). Nanocellulose in food packaging: A review. Carbohydrate Polymers, 255, Article 117479. https://doi. org/10.1016/j.carbpol.2020.117479

Angel, N., Guo, L., Yan, F., Wang, H., \& Kong, L. (2020). Effect of processing parameters on the electrospinning of cellulose acetate studied by response surface methodology. Journal of Agriculture and Food Research, 2, Article 100015. https://doi.org/10.1016/ j.jafr. 2019.100015

Avery, S. V., Singleton, I., Magan, N., \& Goldman, G. H. (2019). The fungal threat to global food security. Fungal Biology, 123(8), 555-557. https://doi.org/10.1016/j. funbio.2019.03.006

Aydemir Sezer, U., Sanko, V., Yuksekdag, Z. N., Uzundağ, D., \& Sezer, S. (2016). Use of oxidized regenerated cellulose as bactericidal filler for food packaging applications. Cellulose, 23(5), 3209-3219. https://doi.org/10.1007/s10570-016-1000-4

Bahl, S., Dolma, J., Jyot Singh, J., \& Sehgal, S. (2021). Biodegradation of plastics: a state of the art review. Materials Today: Proceedings, 39(1), 31-34. https://doi.org/ 10.1016/j.matpr.2020.06.096

Bettaieb, F., Khiari, R., Hassan, M. L., Belgacem, M. N., Bras, J., Dufresne, A., \& Mhenni, M. F. (2015). Preparation and characterization of new cellulose nanocrystals from marine biomass Posidonia oceanica. Industrial Crops and Products, 72, 175-182. https://doi.org/10.1016/j.indcrop.2014.12.038

Bideau, B., Loranger, E., \& Daneault, C. (2018). Nanocellulose-polypyrrole-coated paperboard for food packaging application. Progress in Organic Coatings, 123, 128-133. https://doi.org/10.1016/j.porgcoat.2018.07.003

Bornmann, L., \& Mutz, R. (2015). Growth rates of modern science: A bibliometric analysis based on the number of publications and cited references. Journal of the Association for Information Science and Technology, 66, 2215-2222.

Boufi, S., González, I., Delgado-Aguilar, M., Tarrès, Q., Pèlach, M. A., \& Mutjé, P. (2016) Nanofibrillated cellulose as an additive in papermaking process: A review. Carbohydrate Polymers, 154, 151-166. https://doi.org/10.1016/j. carbpol.2016.07.117

Brink, P. A. (2013). Article visibility: Journal impact factor and availability of full text in PubMed Central and open access. Cardiovascular Journal of Africa, 24(8), 295-296.

Cazón, P., Velazquez, G., Ramírez, J. A., \& Vázquez, M. (2017). Polysaccharide-based films and coatings for food packaging: A review. Food Hydrocolloids, 68, 136-148. https://doi.org/10.1016/j.foodhyd.2016.09.009

de Moura, M. R., Mattoso, L. H. C., \& Zucolotto, V. (2012). Development of cellulosebased bactericidal nanocomposites containing silver nanoparticles and their use as active food packaging. Journal of Food Engineering, 109(3), 520-524. https://doi.org/ 10.1016/j.jfoodeng.2011.10.030

DeLoid, G. M., Cao, X., Molina, R. M., Silva, D. I., Bhattacharya, K., Ng, K. W., \& Demokritou, P. (2019). Toxicological effects of ingested nanocellulose in in vitro intestinal epithelium and in vivo rat models. Environmental Science: Nano, 6(7), 2105-2115. https://doi.org/10.1039/C9EN00184K

Dufresne, A. (2013). Nanocellulose: a new ageless bionanomaterial. Materials Today, 16 (6), 220-227. https://doi.org/10.1016/j.mattod.2013.06.004

EFSA Scientific Committee. (2018). Guidance on risk assessment of the application of nanoscience and nanotechnologies in the food and feed chain: Part 1 , human and animal health. EFSA Journal, 16(7), Article e05327. https://doi.org/10.2903/j. efsa.2018.5327

Fortunati, E., Armentano, I., Zhou, Q., Iannoni, A., Saino, E., Visai, L., Berglund, L. A., \& Kenny, J. M. (2012a). Multifunctional bionanocomposite films of poly(lactic acid), cellulose nanocrystals and silver nanoparticles. Carbohydrate Polymers, 87, 1596-1605. https://doi.org/10.1016/j.carbpol.2011.09.066

Fortunati, E., Peltzer, M., Armentano, I., Torre, L., Jiménez, A., \& Kenny, J. M. (2012b). Effects of modified cellulose nanocrystals on the barrier and migration properties of PLA nano-biocomposites. Carbohydrate Polymers, 90, 948-956. https://doi.org/ 10.1016/j.carbpol.2012.06.025

Freitas, P. A. V., Silva, R. R. A., de Oliveira, T. V., Soares, R. R. A., Junior, N. S., Moraes, A. R. F., \& Soares, N. F. F. (2020). Development and characterization of intelligent cellulose acetate-based films using red cabbage extract for visual detection of volatile bases (March) Lwt, 132, Article 109780. https://doi.org/ 10.1016/j.lwt.2020.109780.
Gan, I., \& Chow, W. S. (2018). Antimicrobial poly(lactic acid)/cellulose bionanocomposite for food packaging application: a review. Food Packaging and Shelf Life, 17, 150-161. https://doi.org/10.1016/j.fpsl.2018.06.012

Garza-Cervantes, J. A., Mendiola-Garza, G., de Melo, E. M., Dugmore, T. I. J., Matharu, A. S., \& Morones-Ramirez, J. R. (2020). Antimicrobial activity of a silvermicrofibrillated cellulose biocomposite against susceptible and resistant bacteria. Scientific Reports, 10(1), 1-7. https://doi.org/10.1038/s41598-020-64127-9

Ghaderi, M., Mousavi, M., Yousefi, H., \& Labbafi, M. (2014). All-cellulose nanocomposite film made from bagasse cellulose nanofibers for food packaging application. Carbohydrate Polymers, 104, 59-65. https://doi.org/10.1016/j.carbpol.2014.01.013

Gorrasi, G., Sorrentino, A., \& Pantani, R. (2015). Modulation of biodegradation rate of poly(lactic acid) by silver nanoparticles. Journal of Polymers and the Environment, 23 (3), 316-320. https://doi.org/10.1007/s10924-015-0720-0

Haghighi, H., Licciardello, F., Fava, P., Siesler, H. W., \& Pulvirenti, A. (2020). Recent advances on chitosan-based films for sustainable food packaging applications. Food Packaging and Shelf Life, 26, Article 100551. https://doi.org/10.1016/j. fpsl.2020.100551

Kamthai, S., \& Magaraphan, R. (2017). Mechanical and barrier properties of spray dried carboxymethyl cellulose (CMC) film from bleached bagasse pulp. In Industrial Crops and Products, 109 pp. 753-761). https://doi.org/10.1016/j.indcrop.2017.09.040 (June).

Khalil, H. P. S. A., Davoudpour, Y., Islam, M. N., Mustapha, A., Sudesh, K., Dungani, R., \& Jawaid, M. (2014). Production and modification of nanofibrillated cellulose using various mechanical processes: a review. Carbohydrate Polymers, 99, 649-665. https://doi.org/10.1016/j.carbpol.2013.08.069

Khare, S., DeLoid, G. M., Molina, R. M., Gokulan, K., Couvillion, S. P., Bloodsworth, K. J., \& Demokritou, P. (2020). Effects of ingested nanocellulose on intestinal microbiota and homeostasis in Wistar Han rats. NanoImpact, 18, Article 100216. https://doi. org/10.1016/j.impact.2020.100216

Klemm, D., Heublein, B., Fink, H. P., \& Bohn, A. (2005). Cellulose: Fascinating biopolymer and sustainable raw material. Angewandte Chemie - International Edition, 44(22), 3358-3393. https://doi.org/10.1002/anie.200460587

Koppolu, R., Lahti, J., Abitbol, T., Swerin, A., Kuusipalo, J., \& Toivakka, M. (2019). Continuous processing of nanocellulose and polylactic acid into multilayer barrie coatings. ACS Applied Materials and Interfaces, 11(12), 11920-11927. https://doi. org/10.1021/acsami.9b00922

MarketsAndMarkets, 2020, Nanocellulose Market by Type, Application, Region - Global Forecast to 2025. Retrieved from https://www.marketsandmarkets.com/MarketReports/nano-cellulose-market-56392090.html (Last accessed on 2021-08-09.).

Matthews, C., Moran, F., \& Jaiswal, A. K. (2021). A review on European Union's strategy for plastics in a circular economy and its impact on food safety. Journal of Cleaner Production, 283, Article 125263. https://doi.org/10.1016/j.jclepro.2020.125263

Menzel, C. (2020). Improvement of starch films for food packaging through a threeprinciple approach: Antioxidants, cross-linking and reinforcement. Carbohydrate Polymers, 250, Article 116828. https://doi.org/10.1016/j.carbpol.2020.116828

Minelli, M., Baschetti, M. G., Doghieri, F., Ankerfors, M., Lindström, T., Siró, I., \& Plackett, D. (2010). Investigation of mass transport properties of microfibrillated cellulose (MFC) films. Journal of Membrane Science, 358(1-2), 67-75. https://doi. org/10.1016/j.memsci.2010.04.030

Mohebi, E., \& Marquez, L. (2015). Intelligent packaging in meat industry: An overview of existing solutions. Journal of Food Science and Technology, 52(7), 3947-3964. https:// doi.org/10.1007/s13197-014-1588-z

Nagaoka, S. (2005). Determinants of high-royalty contracts and the impact of stronger protection of intellectual property rights in Japan. Journal of the Japanese and International Economies, 19(2), 233-254. https://doi.org/10.1016/j.jjie.2005.03.006

Nešić, A., Cabrera-Barjas, G., Dimitrijević-Branković, S., Davidović, S., Radovanović, N., \& Delattre, C. (2020). Prospect of polysaccharide-based materials as advanced food packaging. Molecules, 25(1). https://doi.org/10.3390/molecules25010135

Niu, B., Zhan, L., Shao, P., Xiang, N., Sun, P., Chen, H., \& Gao, H. (2020). Electrospinning of zein-ethyl cellulose hybrid nanofibers with improved water resistance for food preservation. International Journal of Biological Macromolecules, 142, 592-599. https://doi.org/10.1016/j.ijbiomac.2019.09.134

OECD, 2021, Main Science and Technology Indicators. OECD Science, Technology and R\&D Statistics (database). https://doi.org/10.1787/data-00182-en.

Padrão, J., Gonçalves, S., Silva, J. P., Sencadas, V., Lanceros-Méndez, S., Pinheiro, A. C., \& Dourado, F. (2016). Bacterial cellulose-lactoferrin as an antimicrobial edible packaging. Food Hydrocolloids, 58, 126-140. https://doi.org/10.1016/j. foodhyd.2016.02.019

Phanthong, P., Reubroycharoen, P., Hao, X., Xu, G., Abudula, A., \& Guan, G. (2018). Nanocellulose: extraction and application. Carbon Resources Conversion, 1(1), 32-43. https://doi.org/10.1016/j.crcon.2018.05.004

Priya, B., Gupta, V. K., Pathania, D., \& Singha, A. S. (2014). Synthesis, characterization and antibacterial activity of biodegradable starch/PVA composite films reinforced with cellulosic fibre. Carbohydrate Polymers, 109, 171-179. https://doi.org/ 10.1016/j.carbpol.2014.03.044

Rhim, J. W., Park, H. M., \& Ha, C. S. (2013). Bio-nanocomposites for food packaging applications. Progress in Polymer Science, 38(10-11), 1629-1652. https://doi.org/ 10.1016/j.progpolymsci.2013.05.008

Rodríguez-Rojas, A., Arango Ospina, A., Rodríguez-Vélez, P., \& Arana-Florez, R. (2019). ¿What is the new about food packaging material? A bibliometric review during 1996-2016. Trends in Food Science and Technology, 85, 252-261. https://doi.org/ 10.1016/j.tifs.2019.01.016

Rojas-Lema, S., Terol, J., Fages, E., Balart, R., Quiles-Carrillo, L., Prieto, C., \& TorresGiner, S. (2020). Microencapsulation of copper(ii) sulfate in ionically cross-linked chitosan by spray drying for the development of irreversible moisture indicators in paper packaging. Polymers, 12(9). https://doi.org/10.3390/POLYM12092039 
Rudin, A., \& Choi, P. (2013). The Elements of Polymer Science and Engineering (3rd ed..,). Academic Press.

Salama, H. E., Abdel Aziz, M. S., \& Alsehli, M. (2019). Carboxymethyl cellulose/sodium alginate/chitosan biguanidine hydrochloride ternary system for edible coatings. International Journal of Biological Macromolecules, 139, 614-620. https://doi.org/ 10.1016/j.ijbiomac.2019.08.008

Sharma, M., Aguado, R., Murtinho, D., Valente, A. J. M., Mendes De Sousa, A. P., \& Ferreira, P. J. T. (2020). A review on cationic starch and nanocellulose as paper coating components. International Journal of Biological Macromolecules. https://doi. org/10.1016/j.ijbiomac.2020.06.131

Silva, F. A. G. S., Dourado, F., Gama, M., \& Poças, F. (2020). Nanocellulose bio-based composites for food packaging. Nanomaterials. https://doi.org/10.3390/ nano10102041

Śliwińska, M., Wiśniewska, P., Dymerski, T., Namieśnik, J., \& Wardencki, W. (2014). Food analysis using artificial senses. Journal of Agricultural and Food Chemistry, 62(7), 1423-1448. https://doi.org/10.1021/jf403215y

Song, J. H., Murphy, R. J., Narayan, R., \& Davies, G. B. H. (2009). Biodegradable and compostable alternatives to conventional plastics. Philosophical Transactions of the Royal Society B: Biological Sciences, 364(1526), 2127-2139. https://doi.org/10.1098/ rstb.2008.0289
Suhas, Gupta, V. K., Carrott, P. J. M., Singh, R., Chaudhary, M., \& Kushwaha, S. (2016). Cellulose: a review as natural, modified and activated carbon adsorbent. Bioresource Technology, 216, 1066-1076. https://doi.org/10.1016/j.biortech.2016.05.106

Thomas, P., Duolikun, T., Rumjit, N. P., Moosavi, S., Lai, C. W., Bin Johan, M. R., \& Fen, L. B. (2020). Comprehensive review on nanocellulose: Recent developments, challenges and future prospects. Journal of the Mechanical Behavior of Biomedical Materials, 110, Article 103884. https://doi.org/10.1016/j.jmbbm.2020.103884

van Eck, N. J., \& Waltman, L. (2010). Software survey: VOSviewer, a computer program for bibliometric mapping. Scientometrics, 84(2), 523-538. https://doi.org/10.1007/ s11192-009-0146-3

Vila-Lopez, N., \& Küster-Boluda, I. (2020). A bibliometric analysis on packaging research: towards sustainable and healthy packages. British Food Journal, (in, 1956). https://doi.org/10.1108/BFJ-03-2020-0245

Vilarinho, F., Sanches Silva, A., Vaz, M. F., \& Farinha, J. P. (2018). Nanocellulose in green food packaging. Critical Reviews in Food Science and Nutrition, 58(9), 1526-1537. https://doi.org/10.1080/10408398.2016.1270254

World Bank, 2019, Population, total. World Development Indicators. https://data. worldbank.org/indicator/SP.POP.TOTL (Last accessed on 2021-08-07).

Youssef, A. M., \& El-Sayed, S. M. (2018). Bionanocomposites materials for food packaging applications: Concepts and future outlook. Carbohydrate Polymers, 193, 19-27. https://doi.org/10.1016/j.carbpol.2018.03.088 